Supplement of Atmos. Chem. Phys., 21, 10625-10641, 2021

https://doi.org/10.5194/acp-21-10625-2021-supplement

(C) Author(s) 2021. CC BY 4.0 License.

(c) (1)
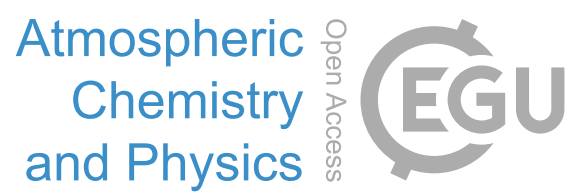

Supplement of

\title{
Mediterranean nascent sea spray organic aerosol and relationships with seawater biogeochemistry
}

Evelyn Freney et al.

Correspondence to: Evelyn Freney (evelyn.freney@uca.fr)

The copyright of individual parts of the supplement might differ from the article licence. 


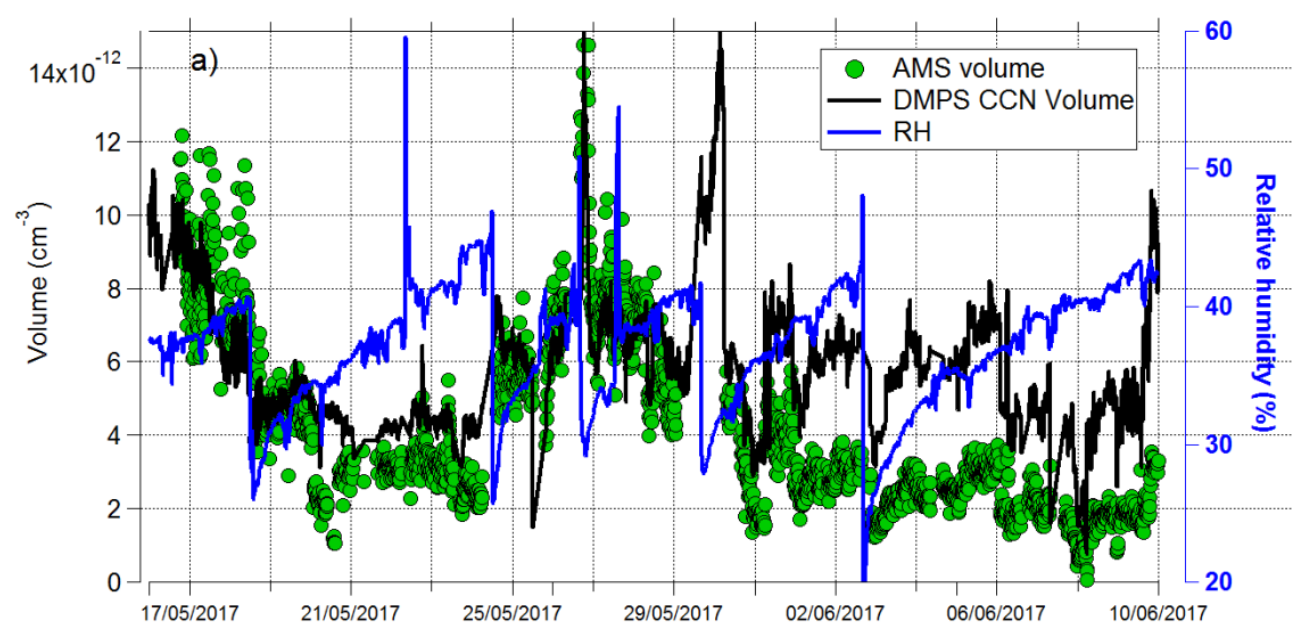

Figure S1: The relative humidty, ACSM volume concentration and DMPS total volume concentration as a function of time.

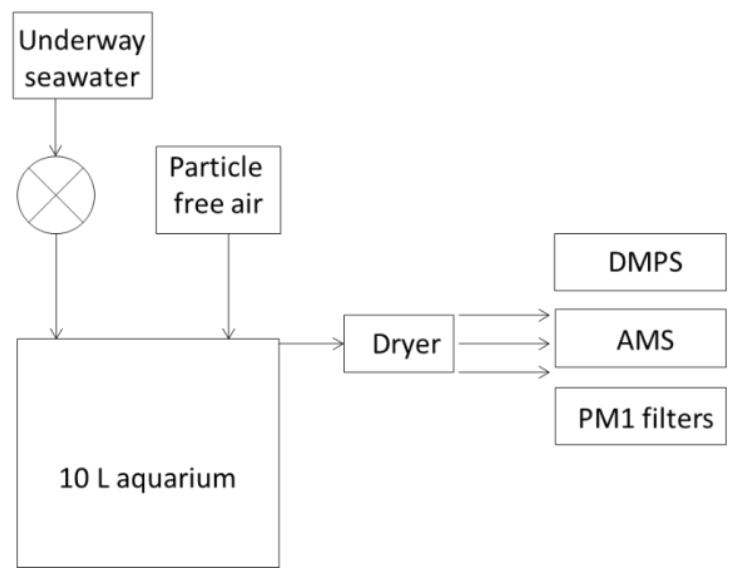

Figure S2. Schematic of sampling set up.
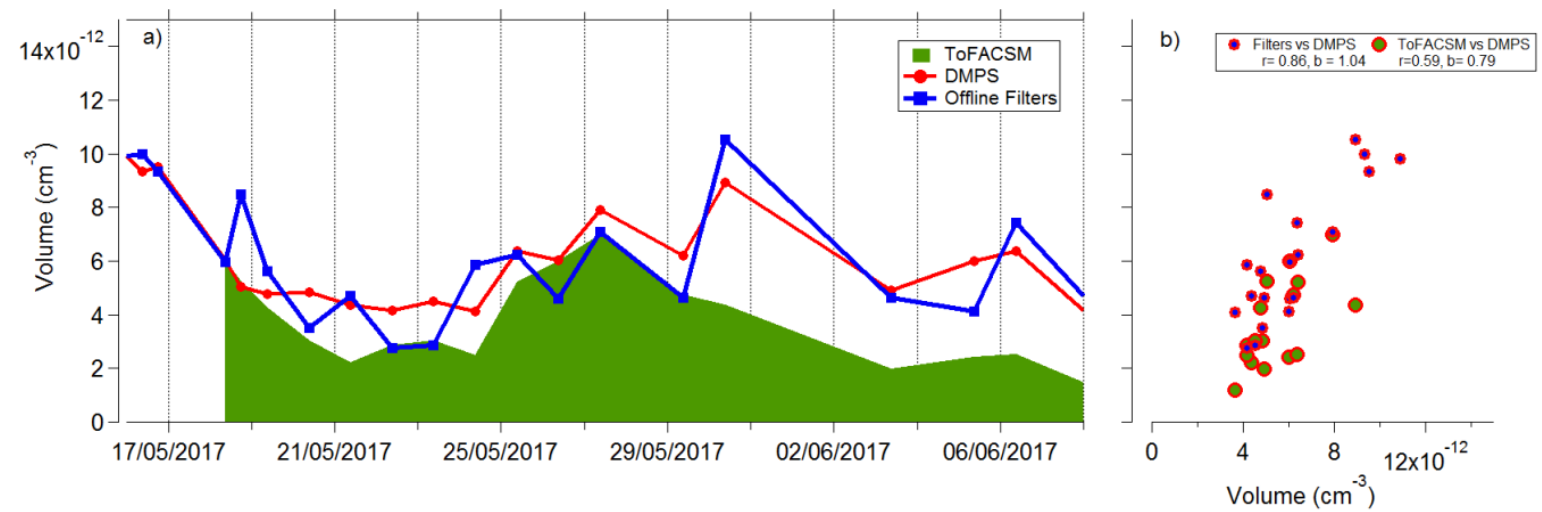

Figure S3: Comparison of volume concentrations obtained from offline filters, DMPS, and ToF-ACSM as a) a function of time and b) comparing concentrations of filters and ACSM with those of the DMPS in a scatter plot. 


\section{Positive matrix factorization (PMF)}

Our choice of factor solution was dependent on a number of different variables, including mass spectra signatures, correlations with reference mass spectra, and time series variability. This data set had very low temporal variability making it difficult to separate species based on the last factor alone. This is also reflected in the small change in average Q/Qexp values across three, four, and five factor solution (see Fig. S4). The PMF analysis was capable of describing $70 \%$ of the total organic mass, with the remaining $30 \%$ being unexplained noise. The fractional contibution of each of the organic factors as a function of time is illustrated in Fig.S5.

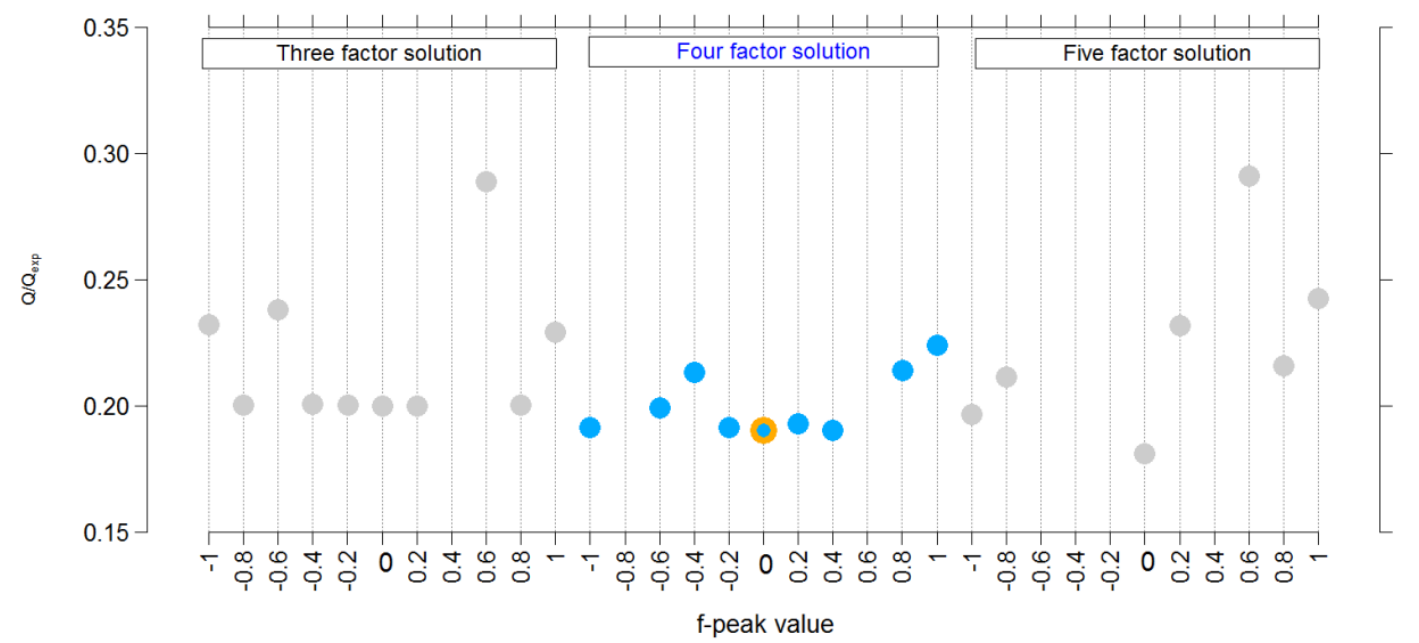

Figure S4. The Q/Qexp results for 3, 4 and 5 factor solutions. The four factor solution (use in the discussion is highlighted in blue. An fpeak value of 0 was chosen (the yellow circle).

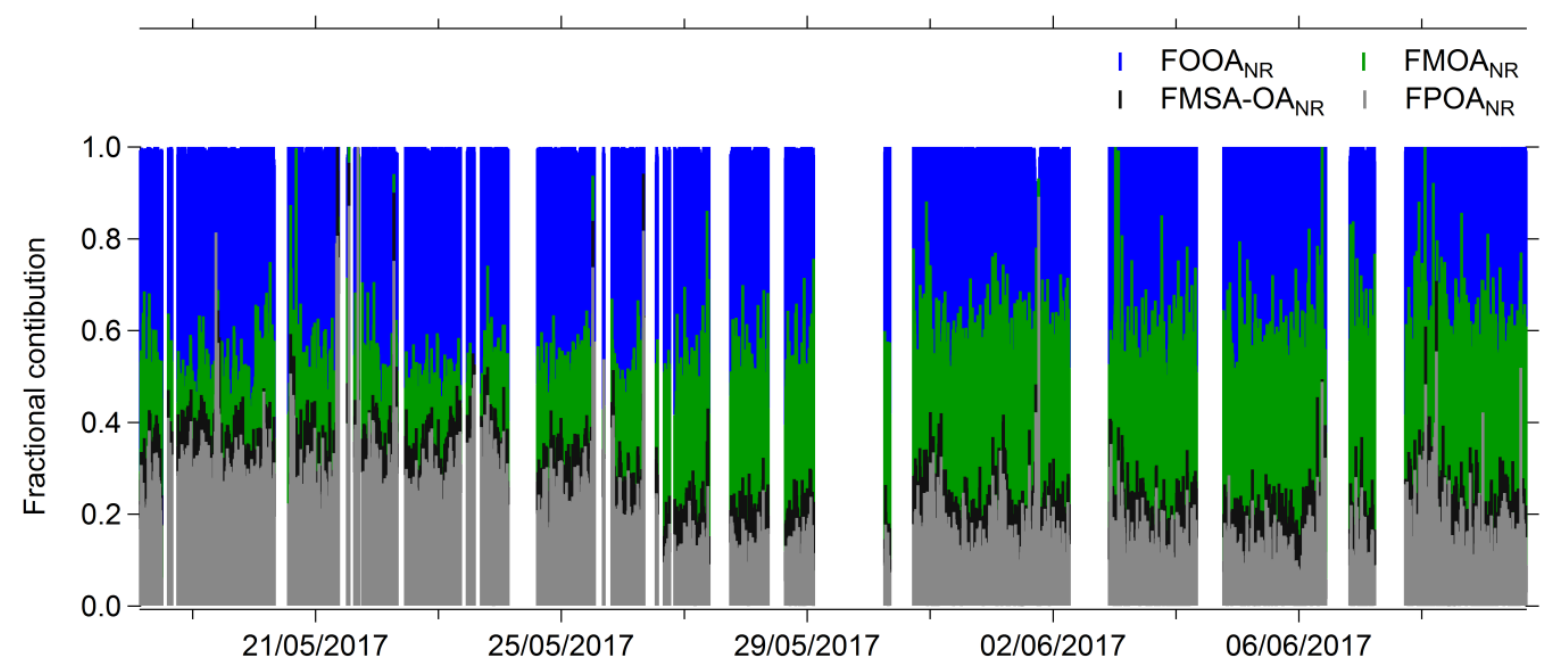

Figure S5. Fractional contribution of species as a function of time

In the two factor solution, an oxidized organic aerosol (OOA) and a second less oxidized species was identified. In the three factor solution, the OOA mass spectral profile remained unchanged and was typical of reference mass spectra for LVOOA (Fig. S6, S7). The less oxidized OA separated into what we refer to as a primary $\mathrm{OA}\left(\mathrm{POA}_{\mathrm{NR}}\right)$ and the marine $\mathrm{OA}\left(\mathrm{MOA}_{\mathrm{NR}}\right)$. The $\mathrm{POA}_{\mathrm{NR}}$ had signature peaks 
for primary organics $\mathrm{m} / \mathrm{z} 55,57$ but also peaks at m/z 69, 71, 91 correlating with mass spectral profiles of proline, valine, palmitic acid and typical hydrocarbon $\mathrm{OA}$ (Fig S7). The $\mathrm{MOA}_{\mathrm{NR}}$ had signature peaks at $\mathrm{m} / \mathrm{z} 41\left(\mathrm{C}_{2} \mathrm{H}_{3} \mathrm{~N}^{+}\right), 70,98,112\left(\mathrm{C}_{6} \mathrm{H}_{12} \mathrm{~N}_{2}^{+}\right), 115,\left(\mathrm{C}_{5} \mathrm{H}_{9} \mathrm{NO}_{2}\right), 117\left(\mathrm{C}_{5} \mathrm{H}_{11} \mathrm{NO}_{2}\right), 119\left(\mathrm{C}_{4} \mathrm{H}_{9} \mathrm{NO}_{3}\right)$, $131\left(\mathrm{C}_{6} \mathrm{H}_{13} \mathrm{NO}_{2}\right)$, and similar to the POA species correlated with reference mass spectral of leucine, proline, and valine, but also with more oxidized reference mass spectra of oxalic acid and malonic acid. It did not contain signature peaks of hydrocarbon species like POA. $\mathrm{POA}_{\mathrm{NR}}$ species were measured in higher concentrations at the start of the sampling with the $\mathrm{MOA}_{\mathrm{NR}}$ taking over near the end of the campaign. This pattern remained consistent in the 3, 4, and 5 factor solutions (Figure S6, 4b in the main text and Fig S9).
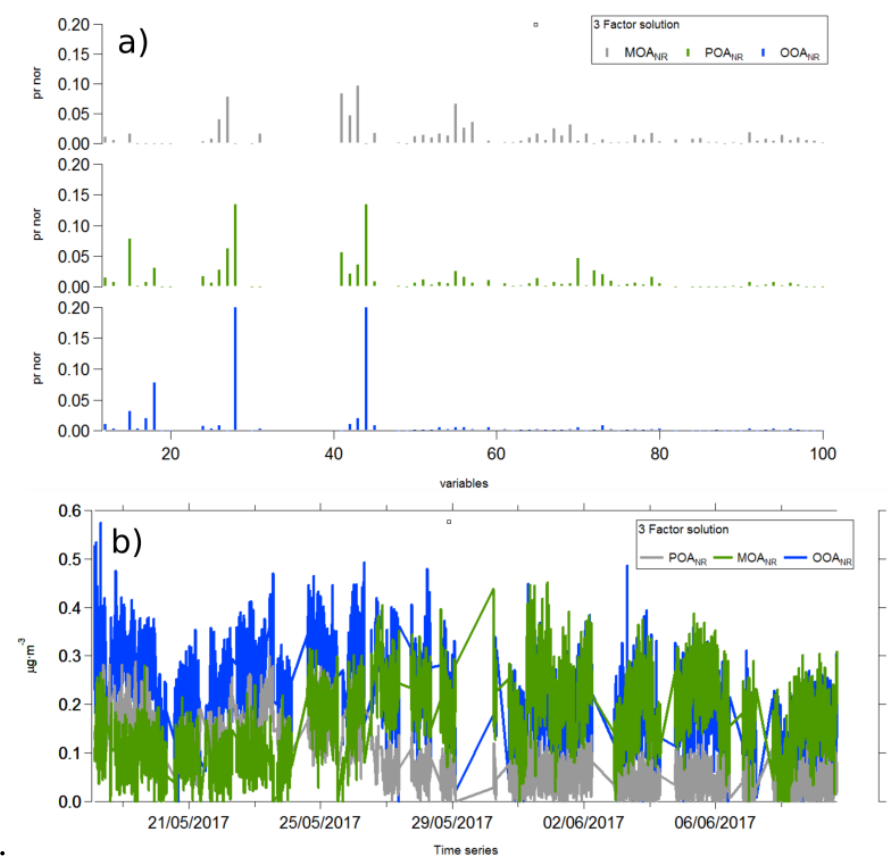

Figure S6: Factor profiles and time-series for the three factor solution. 


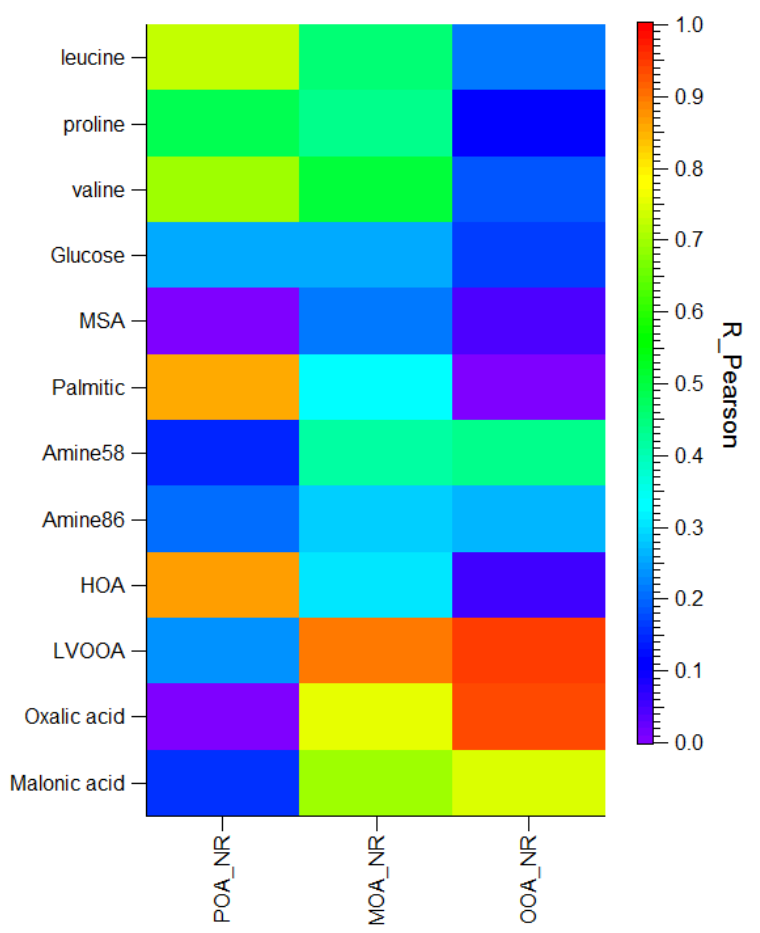

Figure S7: Correlation of the three factor solution profiles with a number of reference mass spectral profiles.

As described in the text a four factor solution was chosen for this data set. The four factor solution included a methanesulphonic (MSA) acid-like OA in addition to the previously identified $\mathrm{MOA}_{\mathrm{NR}}$, $\mathrm{POA}_{\mathrm{NR}}$, and $\mathrm{OOA}_{\mathrm{NR}}$ (Fig 4, main text). The MSA-like factor correlated with the reference mass spectra for MSA (Phinney et al., 2006) with a value of $\mathrm{r}=0.34$ ) (Fig S8). 


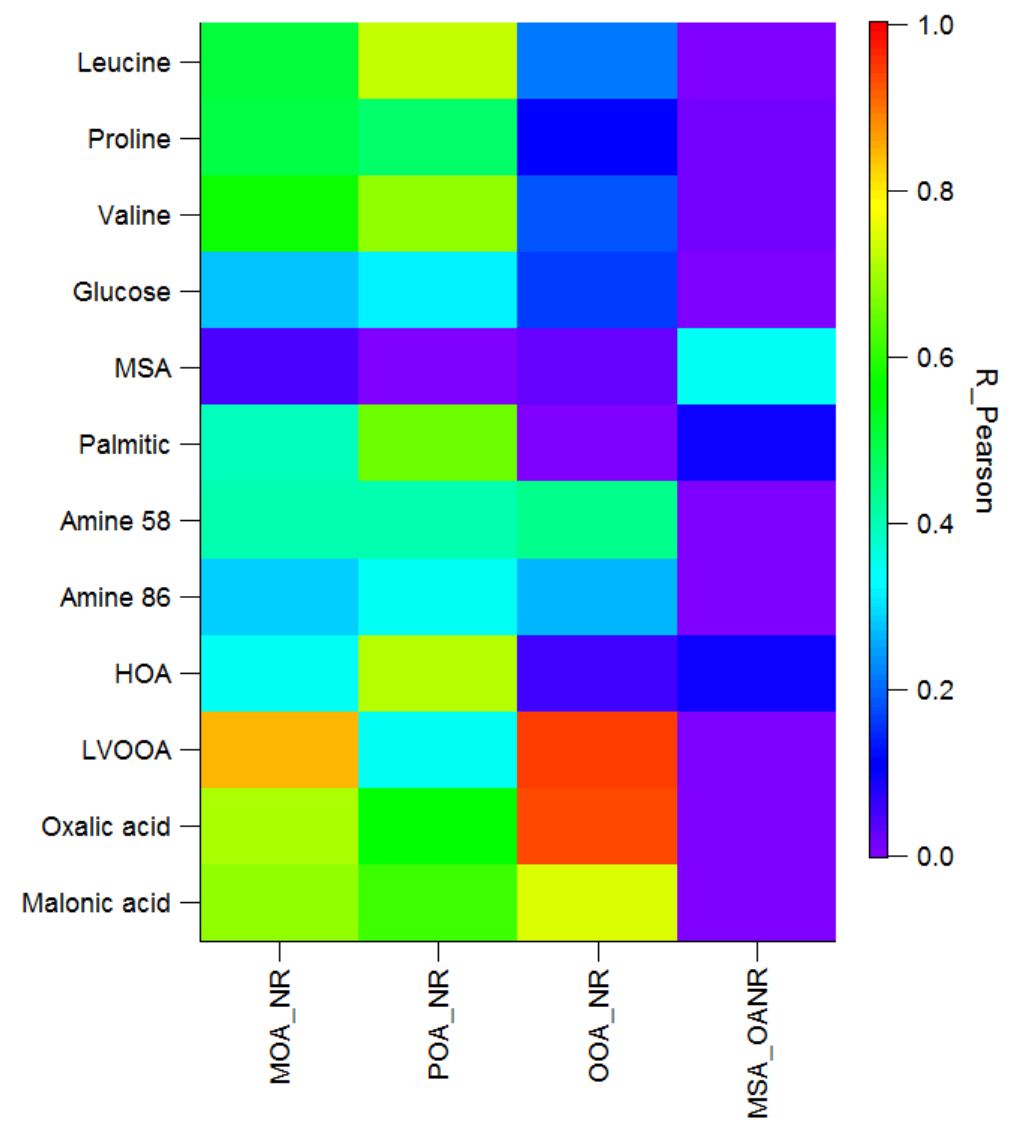

Figure S8: A four factor solution and the corresponding mass spectral profile correlations.

When extending the mass spectral solution to a five factor solution, each of the previous factor profiles were preserved but the $\mathrm{MOA}_{\mathrm{NR}}$ split, giving a species with similar temporal and mass spectral profiles (Fig. S8). 

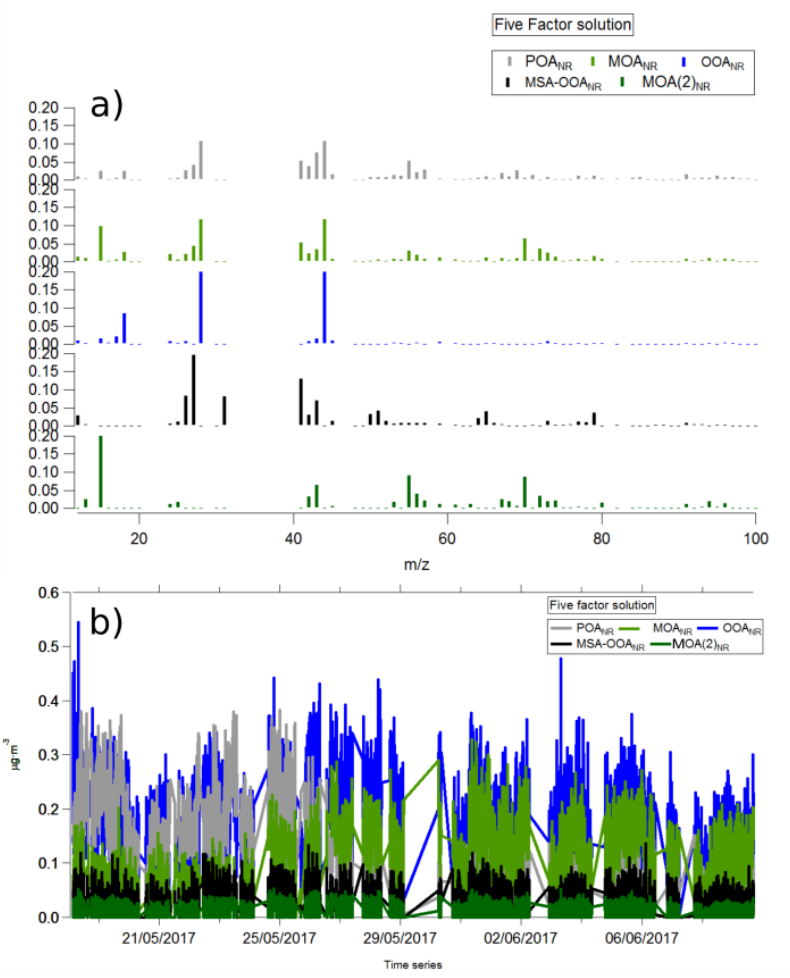

Figure S9: A five factor solution.

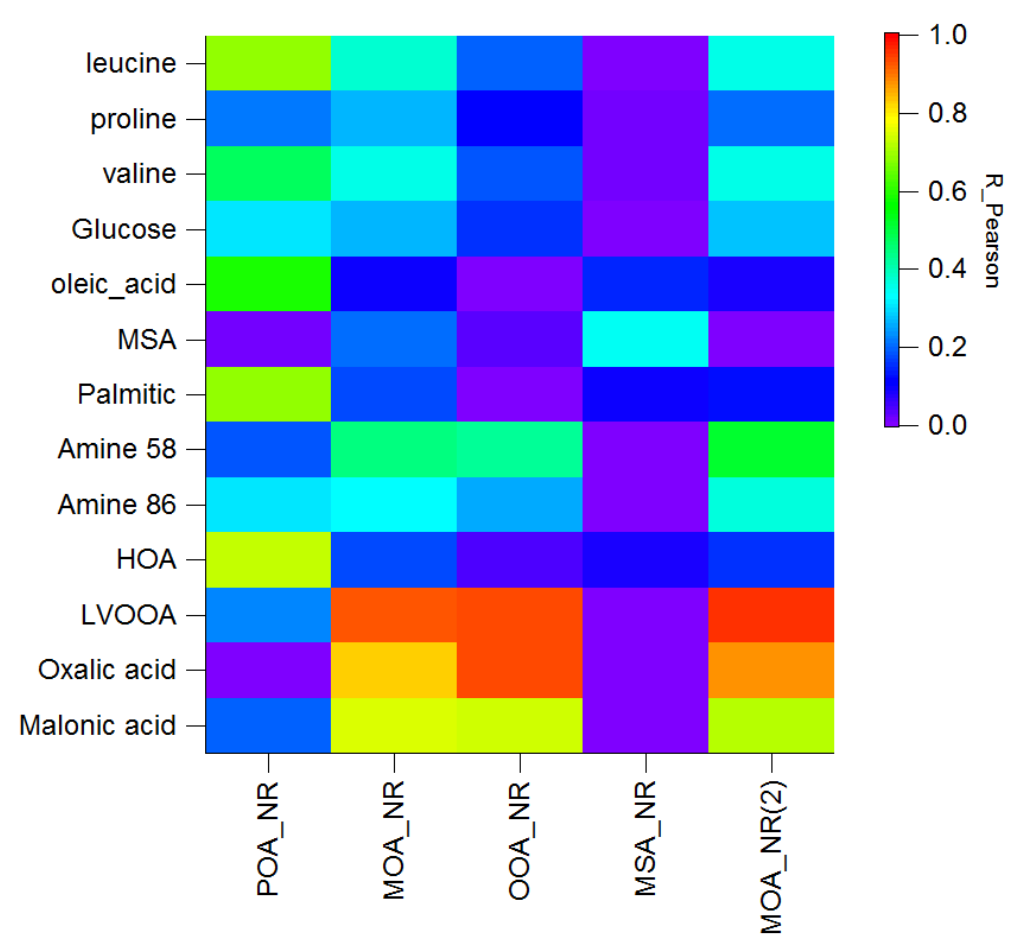

Figures S10 Correlation matrix of five factor correlation. 
a)

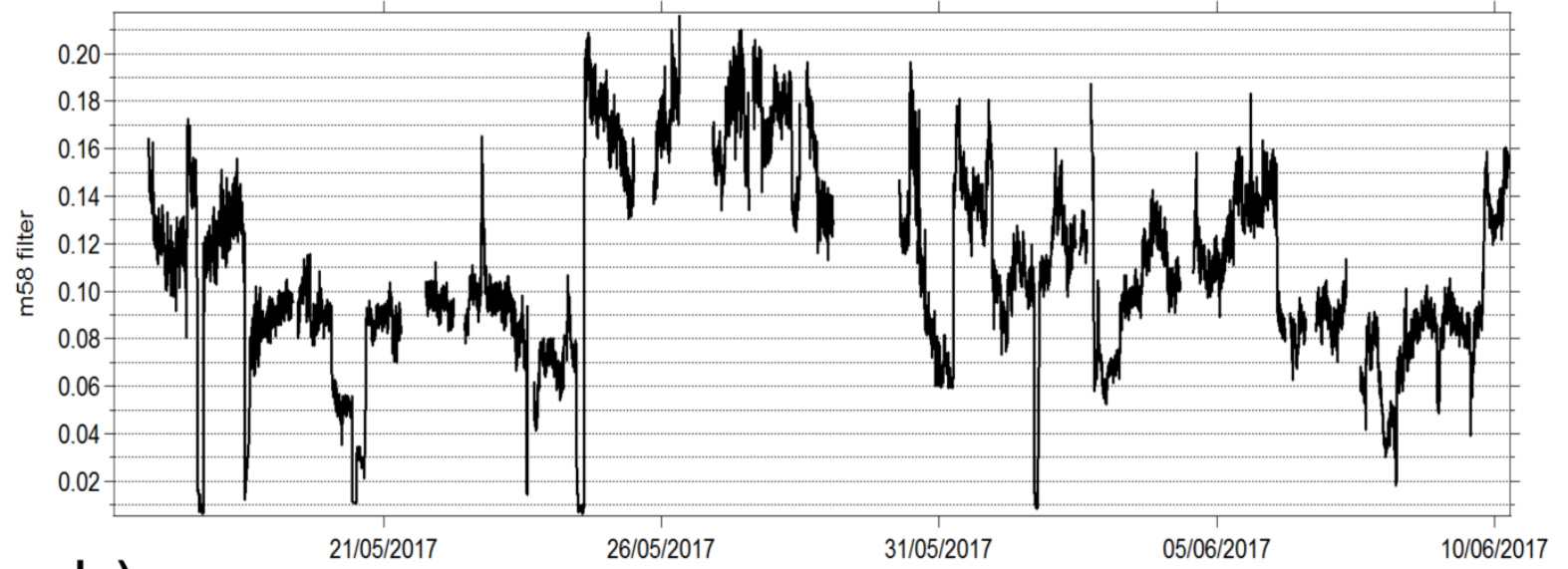

b)

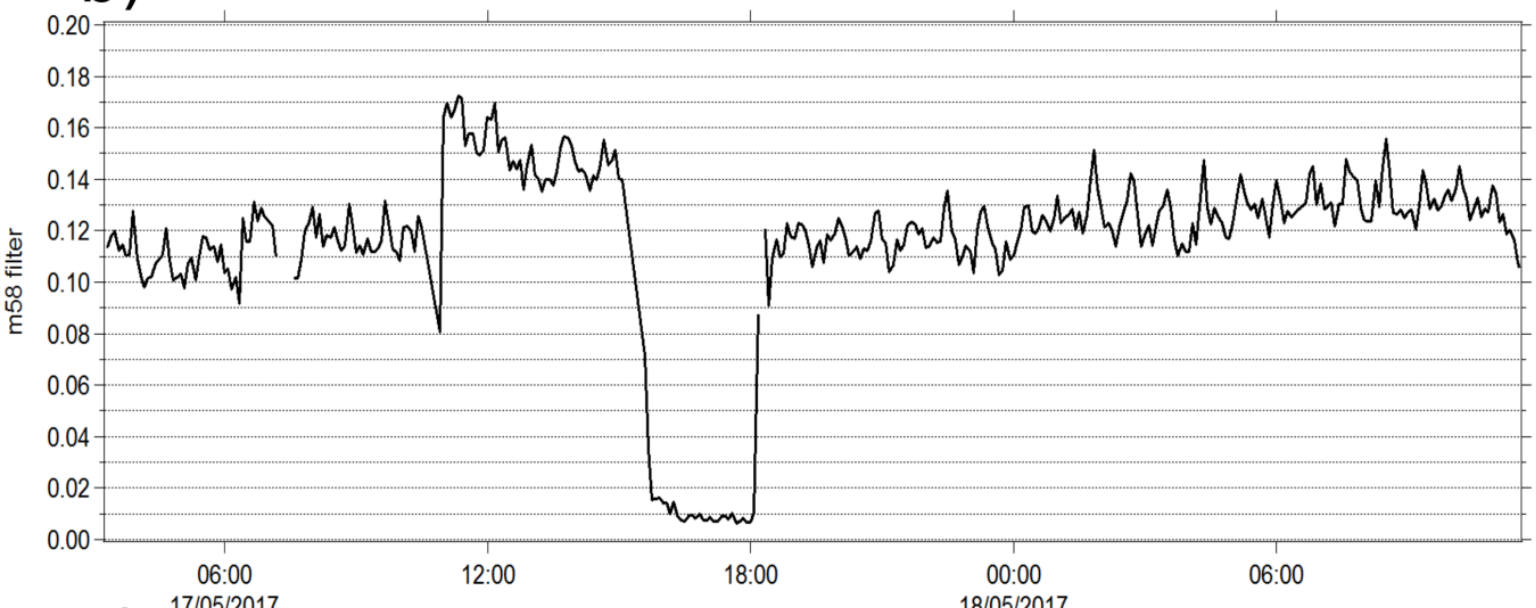

C)

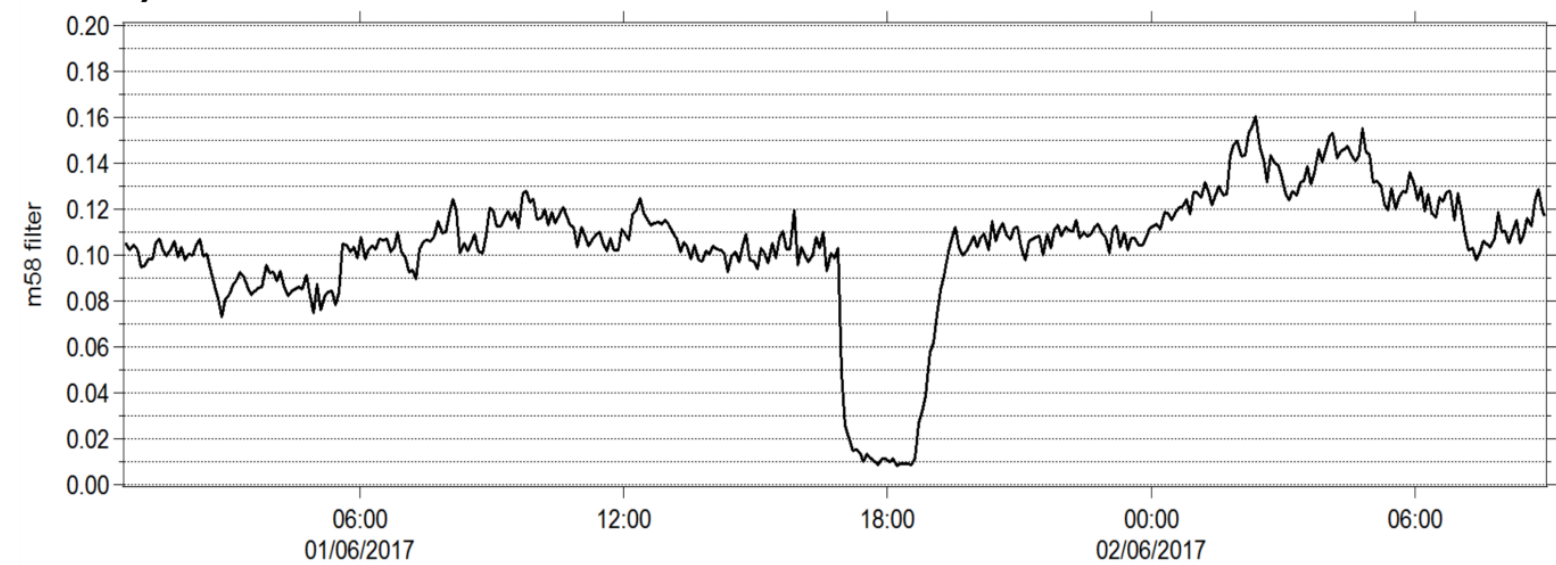

Figure S11: a) Time series of background $\mathrm{m} / \mathrm{z} 58$ (surrogate for $\mathrm{NaCl}$ ), b) Zoom on a particle free sampling period at the start and c) at the end of the sampling period, characterized by a sudden drop is $\mathrm{m} / \mathrm{z}$ signal to $0.02 \mu \mathrm{g} \mathrm{m}^{-3}$ 


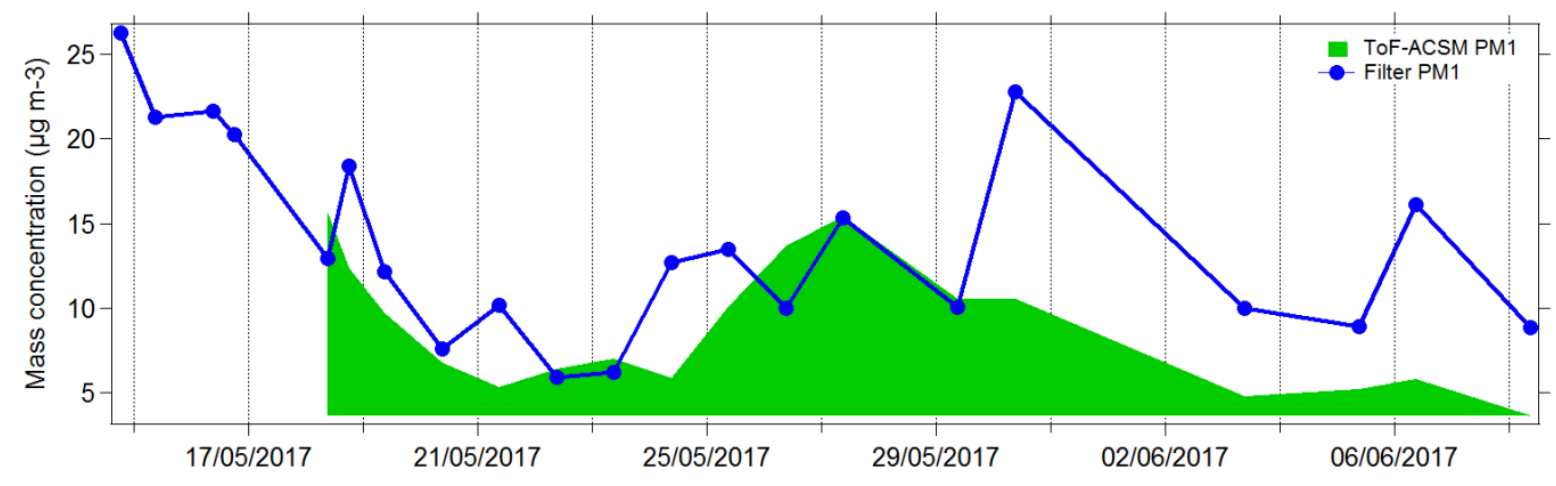

Figure S12. PM1 mass concentrations measured by the ToF-ACSM and the offline Filters.

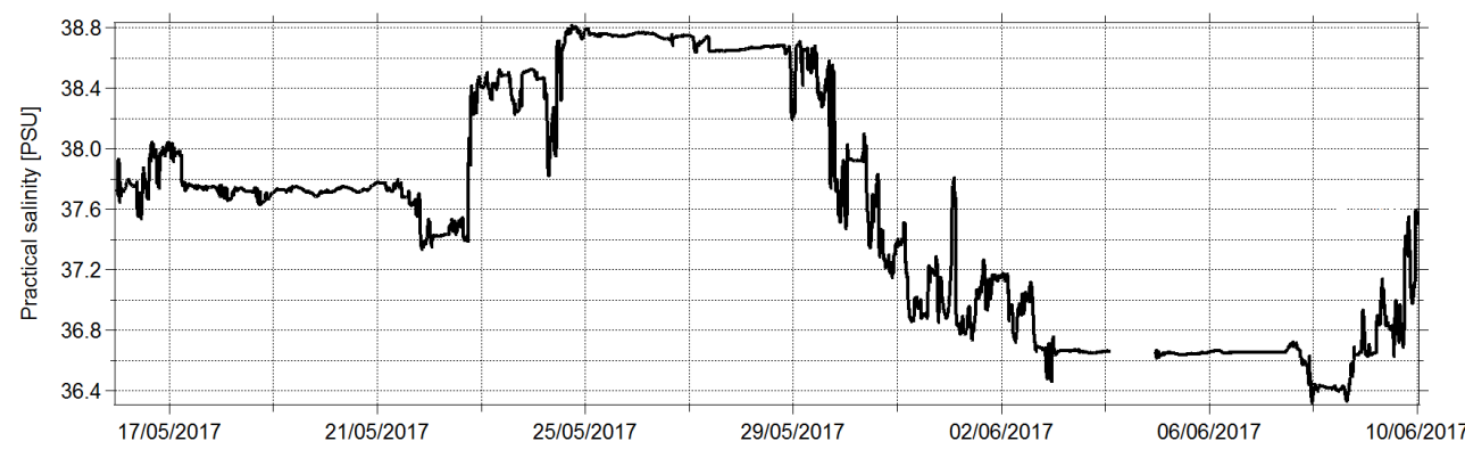

Figure S13 : The practical salinity measurement of the seawater as a function of time.

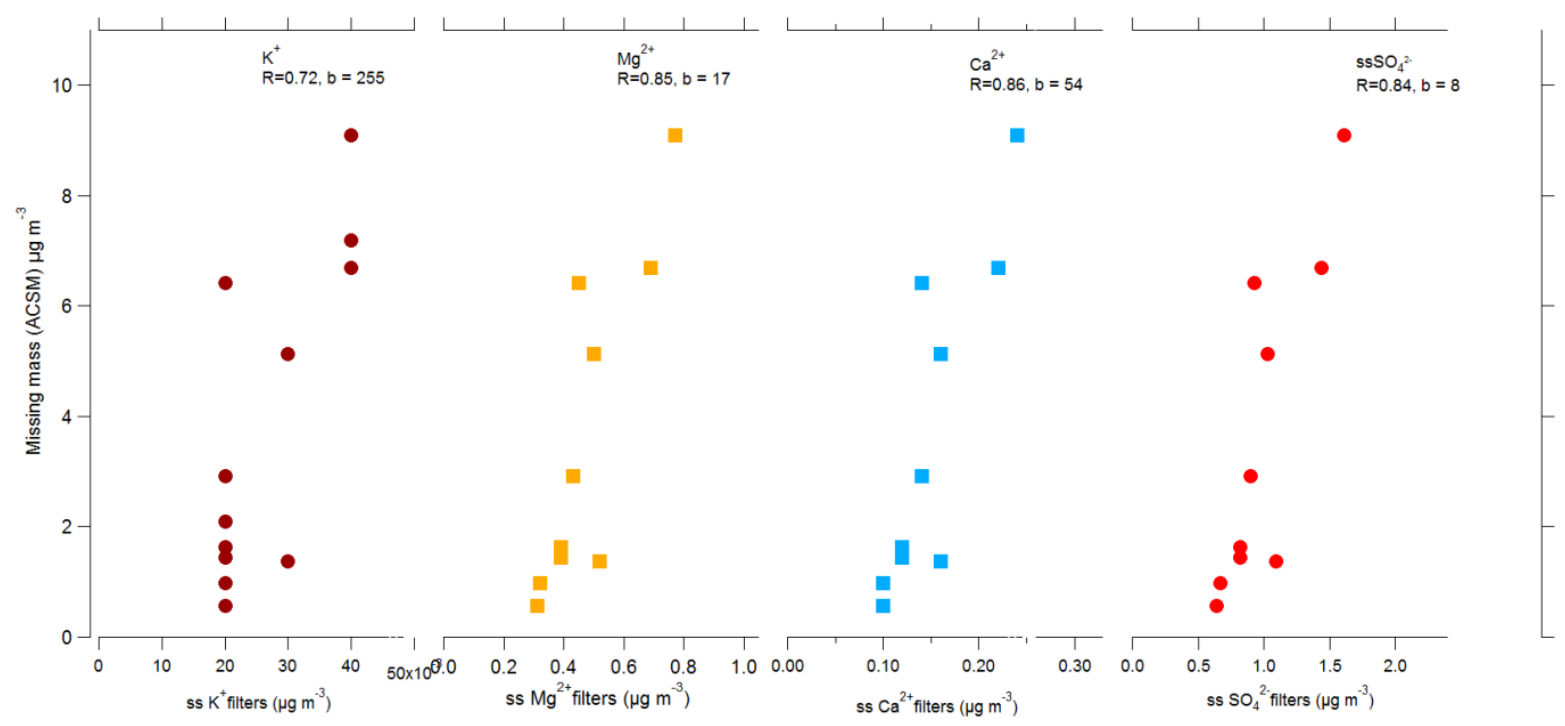

Figure S14: Comparison of the ACSM missing mass with a) $\mathrm{K}_{+}$, b) $\mathrm{Mg}^{2+}$, c) $\mathrm{Ca}^{2+}$, d) $\mathrm{NaCl}$ mass concentrations determined from offline ion chromatography analysis. 


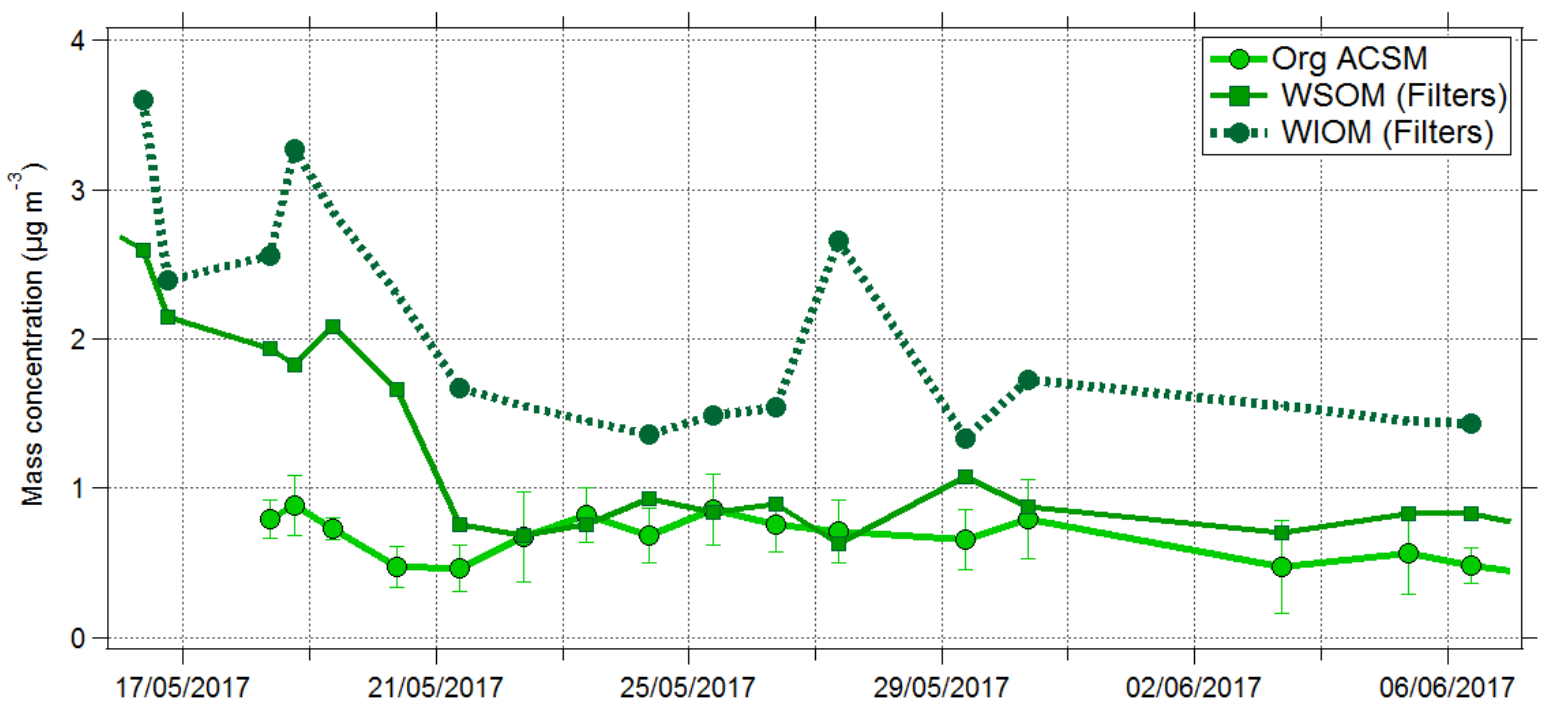

Figure S15: Comparison of organic aerosol measurement by the ACSM with water soluble and water insoluble organic matter (WSOM, WIOM) measured from filters.

\section{Supplementary methods}

\section{Heterotrophic bacteria counts and bacterial production}

For the enumeration of heterotrophic bacteria, discrete samples were collected using a Niskin surface bottle $(<5$ m) at 25 specific stations along the ship transect. Subsamples $(4.5 \mathrm{~mL})$ were fixed with glutaraldehyde grade I $25 \%$ (1\% final concentration) and incubated for $30 \mathrm{~min}$ at $4{ }^{\circ} \mathrm{C}$, then quick-frozen in liquid nitrogen and stored at $-80{ }^{\circ} \mathrm{C}$ until analysis. Samples were thawed at room temperature. Counts were performed on a FACSCanto II flow cytometer (Becton Dickinson) equipped with 3 lasers, red $(633 \mathrm{~nm})$, blue $(488 \mathrm{~nm})$, and violet $(407 \mathrm{~nm})$. For the enumeration of heterotrophic bacteria, cells were stained with SYBR Green I (Invitrogen, Molecular Probes) at $0.025 \%$ ( $\mathrm{vol} / \mathrm{vol}$ ) final concentration for $15 \mathrm{~min}$ at room temperature in the dark. Stained cells were discriminated and enumerated according to their right-angle light scatter (SSC) and green fluorescence using a 530/30 nm bandpass filter. In a plot of green versus red fluorescence, heterotrophic bacteria were distinguished from autotrophic prokaryotes. Fluorescent beads ( $1.002 \mu \mathrm{m}$; Polysciences Europe) were systematically added to each analyzed sample as an internal standard. The cell abundance was determined from the flow rate, which was calculated with TruCount beads (BD Biosciences).

Heterotrophic prokaryotic production (BP) was estimated from rates of ${ }^{3} \mathrm{H}$ leucine incorporation using the micro centrifugation technique. The detailed protocol is available in Van Wambeke et al. (2020). Briefly, triplicate 1.5 $\mathrm{mL}$ subsamples from the Niskin surface bottle $(<5 \mathrm{~m})$ and one blank were incubated in the dark at in-situ temperature. Leucine was added at $20 \mathrm{nM}$ final concentration and the leucine - carbon conversion factor used was $1.5 \mathrm{kgC} \mathrm{mol}^{-1}$. 